\title{
Solar Photochemical Reduction and Oxidation of Water and Related Aspects
}

\author{
S.R. Lingampalli ${ }^{1}$ and C.N.R. Rao ${ }^{1}$
}

Conversion of solar energy to useful chemicals has become necessary for finding solutions to energy and environmental issues. One of the means is to use of solar energy for the reduction of water to generate hydrogen or for the reduction of $\mathrm{CO}_{2}$ to useful chemicals. In spite of substantial effort, the discovery of stable and efficient photocatalysts remains a challenge, although some encouraging results have been reported. In this article, we provide a brief perspective of the current status of solar water splitting and reduction of $\mathrm{CO}_{2}$.

Keywords: Artificial Photosynthesis; Hydrogen Generation; Oxygen Evolution; Photocatalysis; Reduction of $\mathrm{CO}_{2}$; Water Splitting.

\section{INTRODUCTION}

Use of solar energy to produce sustainable chemical fuels is an important means of solving the serious energy problem. These chemical fuels include production of high energy density hydrogen, carbon monoxide, methanol, methane, etc. This objective is achievable by mimicking natural photosynthesis artificially in the laboratory, generally referred to as artificial photosynthesis ${ }^{1}$. Artificial photosynthesis is a fascinating topic of research wherein hydrogen is produced from water by photochemical or photoelectrochemical means ${ }^{2}$. Besides generation of hydrogen by using solar irradiation, photochemical reduction of $\mathrm{CO}_{2}$ to useful chemicals is equally important, since elimination of $\mathrm{CO}_{2}$ or decrease of its concentration in the atmosphere is a burning problem facing mankind.

In photocatalytic splitting of water, solar energy is stored in the form chemical bonds in hydrogen associated with a Gibbs free energy change of $+237 \mathrm{~kJ} / \mathrm{mol}$. Akin to natural photosynthesis, it is an uphill reaction. In this article, we present the basics and recent developments in photochemical water splitting and also discuss recent progress in the reduction of $\mathrm{CO}_{2}$.

\section{NATURAL VERSUS ARTIFICIAL PHOTOSYNTHESIS}

\subsection{Natural photosynthesis}

Solar energy is stored in the form of chemical bonds in the process of natural photosynthesis. In natural photosynthesis, two pigments, P700 and P680 play a crucial role in the light absorption and in the cascade of electron-relay channels assisting the spatial separation of charges with an efficiency of near unity. This process is also known as the Z-scheme. Holes confined to photosystem II are efficiently utilized by the water oxidation complex (WOC) for the oxidation of water whereas the electrons confined to photosystem I are efficiently utilized for the reduction of NADP ${ }^{+}$to NADPH. NADPH is used for the reduction of $\mathrm{CO}_{2}$ to carbohydrates in subsequent dark reactions.

\subsection{Artificial photosynthesis}

The principles of natural photosynthesis are successfully adopted and embedded in artificial systems based on the use of advanced materials ${ }^{3,4}$. The design and processing of photocatalysts has resulted in the discovery of several

\footnotetext{
${ }^{1}$ New Chemistry Unit, International Centre for Materials Science (ICMS), Sheikh Saqr Laboratory, Jawaharlal Nehru Centre for Advanced Scientific Research (JNCASR), Jakkur P.0., Bangalore-560064, India. Correspondence should be addressed to C.N.R.R. (cnrrao@jncasr.ac.in). Published online 28 February 2018; doi:10.1142/S2529732518500013

This is an Open Access article published by World Scientific Publishing Company. It is distributed under the terms of the Creative Commons Attribution 4.0 (CC-BY) License. Further distribution of this work is permitted, provided the original work is properly cited.
} 
promising photocatalysts for the splitting of water to hydrogen and oxygen. Half-reactions of the reduction and oxidation of water are as follows:

$\mathrm{H}_{2} \mathrm{O} \rightarrow \mathrm{H}_{2}+1 / 2 \mathrm{O}_{2}\left(\Delta \mathrm{G}=+237 \mathrm{~kJ} \mathrm{~mol}^{-1}, \Delta \mathrm{E}^{0}=1.23 \mathrm{~V}\right)$

Reduction half-reaction: $4 \mathrm{H}^{+}+4 \mathrm{e}^{-} \rightarrow 2 \mathrm{H}_{2}$ (0 V vs. NHE)

Oxidation half-reaction: $2 \mathrm{H}_{2} \mathrm{O} \rightarrow 4 \mathrm{H}^{+}+\mathrm{O}_{2}$

$$
+4 \mathrm{e}^{-}(1.23 \mathrm{~V} \text { vs. NHE) }
$$

The entire process of photocatalytic water splitting is divided into three steps (Figure 1). They are,

(i) Absorption of photons of sufficient energy by the photocatalyst

(ii) Generation, separation and migration of charge carriers to the active sites

(iii) Reduction of water and oxidation of water at respective reaction sites

One can choose suitable photocatalysts for the splitting of water based on their band edge positions relative to the reduction potentials of water reduction and oxidation. As shown in Figure 1, a semiconductor with a negative conduction band (CB) and positive valence band (VB) relative to the water reduction and oxidation potentials, respectively, is thermodynamically suitable for splitting water. The process can be either one-step or two-step depending on the process involved (Figure 2). Generation of one electron and one hole, requires one photon in a one-step process whereas it requires two photons in a two-step process. The physical and chemical processes involved in photocatalytic water splitting have different time scales. Generally, the time scales of surface redox reactions (water reduction and oxidation) are longer compared to either recombination or relaxation. Therefore, finding suitable means to prolong the life-times of charge carriers is essential.

\section{WATER SPLITTING}

Producing hydrogen and oxygen from water in a ratio of 2:1 is known as water splitting. Photocatalysts employed for water splitting range from wide bandgap to narrow bandgap semiconductors. Generally, narrow band gap materials are preferred for the solar energy conversion process owing to their capacity to absorb maximum fraction of sunlight. It is common practice to modify the electronic band structure of wide band gap materials by doping or forming solid solutions for the efficient sunlight harvesting. To evaluate the activity of water reduction and oxidation independently, it is customary to use sacrificial agents. For the reduction of water, the sacrificial electron donors such as $\mathrm{Na}_{2} \mathrm{~S}-\mathrm{Na}_{2} \mathrm{SO}_{3}$, methanol, benzyl alcohol are used. Scavenger quickly consumes holes and leaves behind the excited electrons. These electrons possess longer life-time and can be efficiently utilized. Similarly,
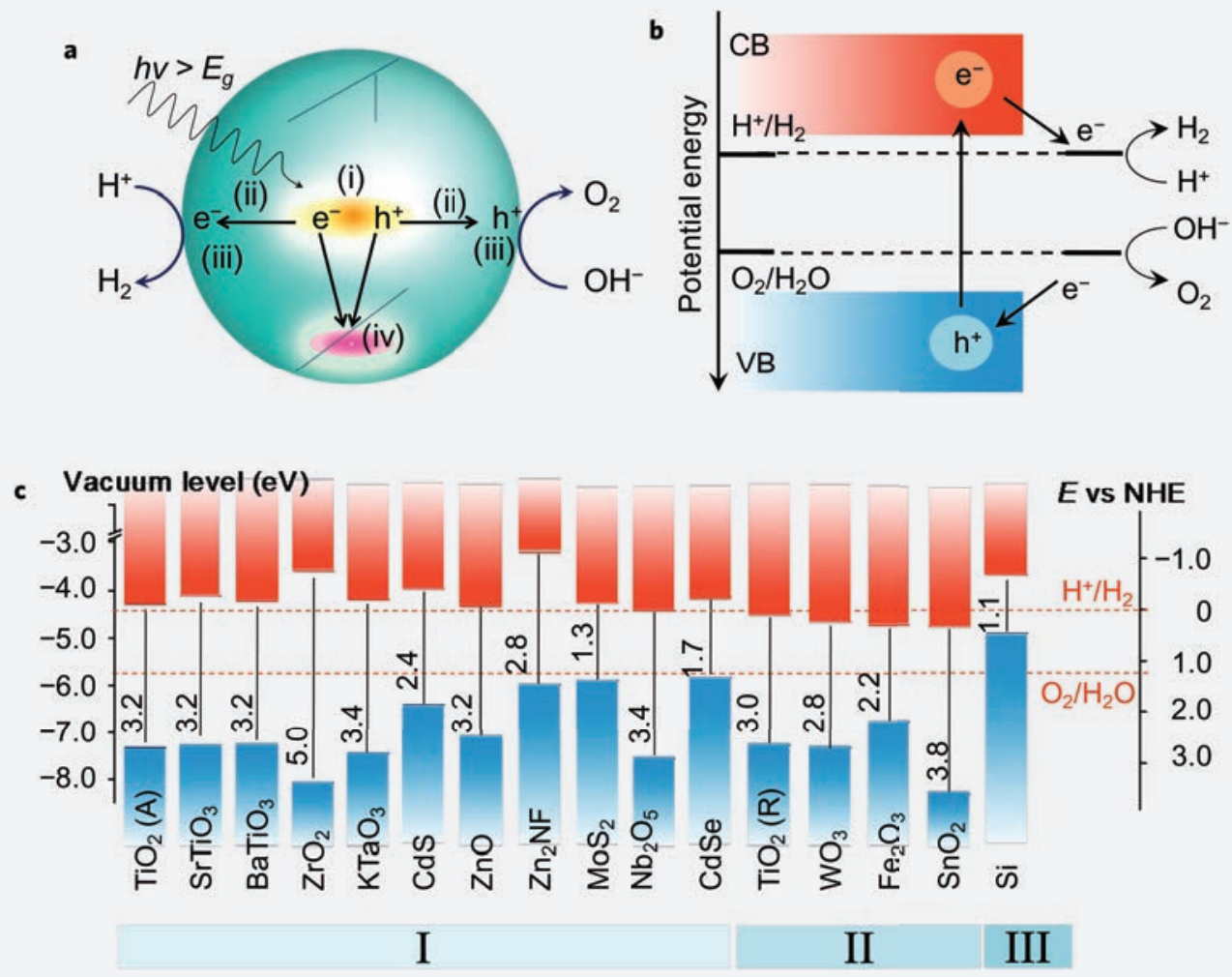

Figure 1.Schematic rep-
resentation of (a) the
steps involved and (b)
relative energy levels
of photocatalytic water
splitting. (c) Comparison
of band positions of
semiconductors relative
to the redox potentials
of water. Reproduced
with permission from
Ref. 3. Copyright 2015 ,
Wiley-VCH Verlag GmbH
\& Co. KGaA, Weinheim. 

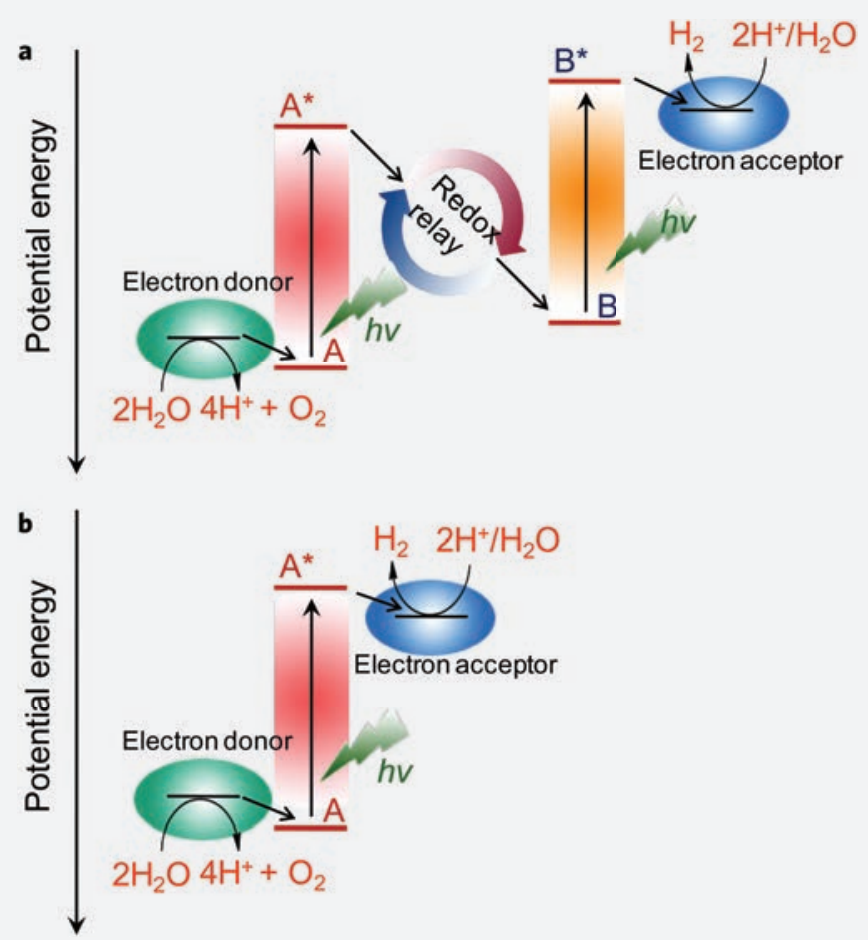

Figure 2. Schematic representation of mechanism of (a) two-step and (b) one-step water splitting. Reproduced with permission from Ref. 3. Copyright 2015, Wiley-VCH Verlag GmbH \& Co. KGaA, Weinheim.

electron acceptors such as $\mathrm{AgNO}_{3}$ and $\mathrm{Na}_{2} \mathrm{~S}_{2} \mathrm{O}_{8}$ are used for the oxidation of water.

\subsection{Overall water splitting}

Of the photocatalysts that have been discovered, several of the materials contain the metal ions with $\mathrm{d}^{0}$ or $\mathrm{d}^{10}$ configuration $^{5}$. These include metal oxides such as $\mathrm{TiO}_{2}, \mathrm{ZrO}_{2}, \mathrm{Ta}_{2} \mathrm{O}_{5}$, $\mathrm{Nb}_{2} \mathrm{O}_{5}$, etc. In these oxides $02 p$ states form the VB and it exists deep down in energy therefore the VB is sufficiently positive relative to water oxidation potential. Their $C B$ is slightly negative relative to the water reduction potential. However, they possess wide band gaps and are less promising for the solar absorption. Wide band gap metal nitrides such as $\beta-\mathrm{Ge}_{3} \mathrm{~N}_{4}$ and $\mathrm{GaN}$ and sulphides such as $\mathrm{ZnS}$ have also been employed. In nitrides and sulphides, the VB consists of states originating from $N 2 p$ and $S 3 p$ respectively. Photocatalytic activity of the wide band gap materials can be improved by various means. For example, doping of metals such as $R$, $\mathrm{V}$, Mo, etc. or doping of non-metals such as C, N, B, S, etc. in $\mathrm{TiO}_{2}{ }^{6}$. Photocatalytic activity of substituted $\mathrm{TiO}_{2}$ is greatly influenced by the ability of the dopant to trap and transfer the charges depending on the distribution and electronic configuration of the dopant ions ${ }^{6}$. Doping of anions such as N, S and $\mathrm{P}$ alters the $\mathrm{VB}$. Doping of $\mathrm{F}^{-}, \mathrm{Cl}^{-}$and $\mathrm{Br}^{-}$ions also cause an increase in hydrogen evolution activity although their impact on electronic structure is marginal. Substitution of $\mathrm{N}$ in place of 0 elevates the VB due to mixing of $02 p$ and $N 2 p$ orbitals causing a decrease in energy gap.

Substitution of $\mathrm{N}$ alone in place of 0 in an oxide results in charge imbalance and increases the number of anion vacancies. However cosubstitution of $\mathrm{N}$ with $\mathrm{F}$ in place of 0 would not cause any change, due to balance of charges. This also significantly changes the electronic structure rendering visible absorption of the material. It causes a decrease in band gap from 3.2 to 2.4 $\mathrm{eV}$ with a reduction in band gap of $0.6 \mathrm{eV}$ in the case of $\mathrm{ZnO}^{7}$. Similarly, a red-shift in absorption onset in the case of $\mathrm{TiO}_{2}$ is observed with $\mathrm{N}$ and $\mathrm{F}$ cosubstitution $^{8}$. It also exhibits hydrogen evolution of $60 \mu \mathrm{mol} \mathrm{h}{ }^{-1} \mathrm{~g}^{-1}$ under visible-light irradiation in the presence of $\mathrm{Na}_{2} \mathrm{~S}-\mathrm{Na}_{2} \mathrm{SO}_{3}$.

Combinations of metal oxides with metals have been well explored. Often Pt, $\mathrm{Au}, \mathrm{Ru}, \mathrm{Rh}, \mathrm{Pd}$ and $\mathrm{Ag}$ are used as cocatalysts for water reduction $^{6}$. The activity obtained with Pt is generally superior due its low over potential and high work function. $\mathrm{Au}$ and $\mathrm{Ag}$ nanoparticles also serve as visible-light responsive materials due to their surface plasmon resonance band in the visible region. The excited electrons in the metal nanoparticles are injected into the CB of the oxides. It has been found recently that activity of such materials depends on the shape, size and other factors. For example, Janus structures of $\mathrm{Au}-\mathrm{TiO}_{2}$ exhibit superior activity $\left(\sim 46 \mathrm{~mL} \mathrm{~h}^{-1}\right)$ over coreshell Au- $\mathrm{TiO}_{2}\left(\sim 26 \mathrm{~mL} \mathrm{~h}^{-1}\right)$ whereas amorphous $\mathrm{TiO}_{2}$ and bare Au show negligible hydrogen evolution yields (Figure 3$)^{9}$.

Solid solutions of semiconductors are interesting due to their unique optical and photocatalytic properties. For example, solid solutions of $\mathrm{ZnO}$ and GaN such as $\mathrm{Zn}_{1-x} \mathrm{Ga}_{x} \mathrm{O}_{1-x} \mathrm{~N}_{x}$ exhibit remarkable lowering of the band gap ${ }^{10}$. This results in photocatalytic activity under irradiation of visible-light alone. $\mathrm{Zn}_{1-x} \mathrm{Ga}_{x} \mathrm{O}_{1-x} \mathrm{~N}_{x}$ exhibits hydrogen evolution of $320 \mu \mathrm{mol} \mathrm{h}^{-1}$ and oxygen evolution of $160 \mu \mathrm{mol} \mathrm{h}^{-1}$ simultaneously under visible-light irradiation from water in acidic medium. It should be noted that both the parent materials, $\mathrm{ZnO}$ and $\mathrm{GaN}$, are inactive for water splitting under visible-light irradiation. Here, $\mathrm{RuO}_{2}$ is employed as hydrogen evolution cocatalyst. The ratio of $\mathrm{H}_{2}$ and $\mathrm{O}_{2}$ is 2:1 as expected for an ideal water splitting reaction. Quantum yield (QY) values depicted in the Figure 4 match with the optical absorption spectrum and the photocatalyst is inactive under irradiation of long wavelength photons. The photocatalytic activity however, extends from UV to visible region and is found to be consistent over several cycles. 


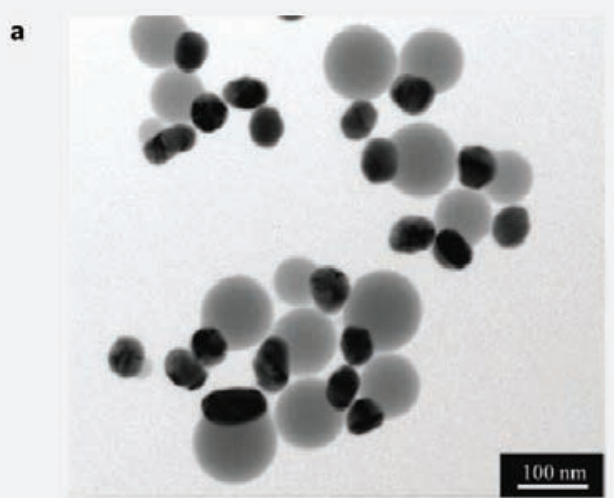

b

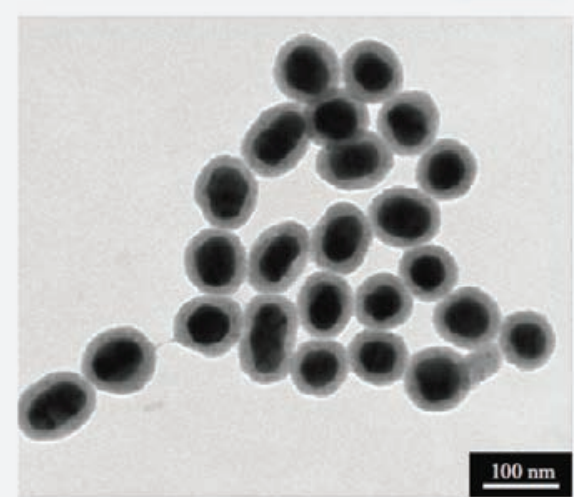

c

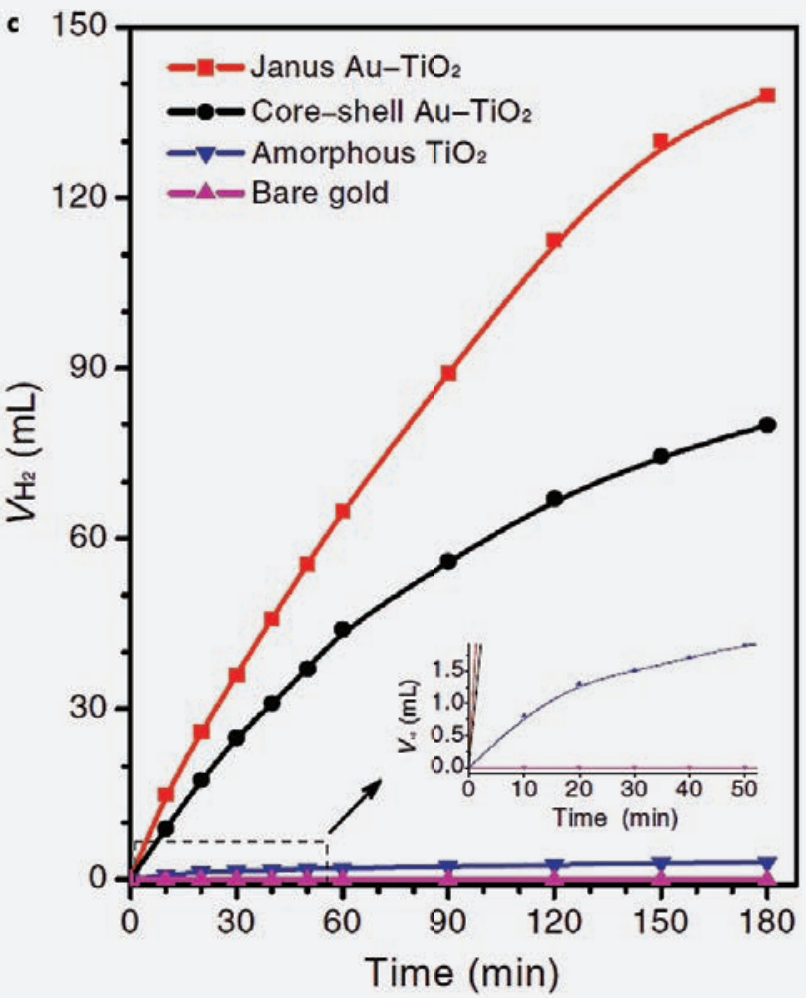

Figure 3. TEM images of (a) Janus and (b) core-shell Au-TiO ${ }_{2}$ nanostructures. (c) Hydrogen generated under visible-light irradiation using Janus and core-shell Au-TiO ${ }_{2}$ nanostructures and related compounds. Reproduced with permission from Ref. 9.
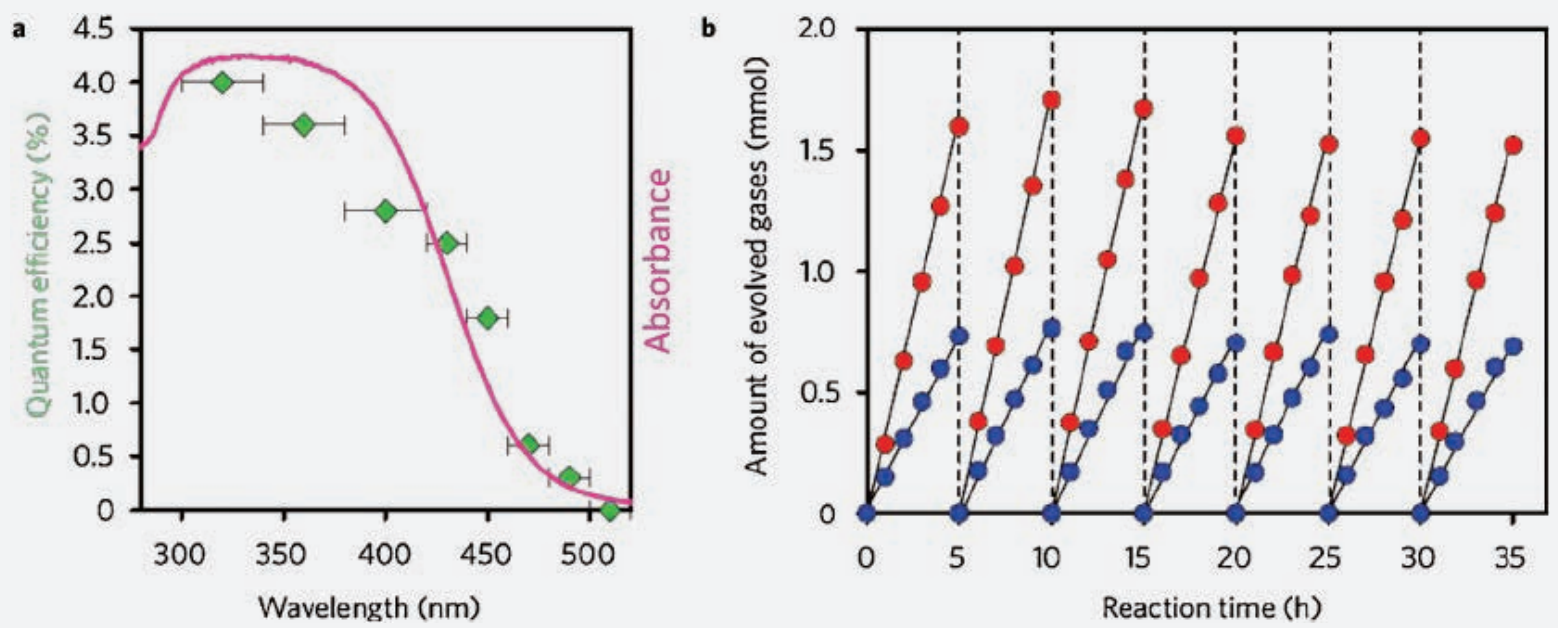

Figure 4. (a) Comparison of quantum efficiencies with the absorption spectrum of ZnO:GaN. (b) Rate of evolution of $\mathrm{H}_{2}$ and $\mathrm{O}_{2}$ with $\mathrm{ZnO}$ :GaN. Reproduced with permission from Ref. 10. Copyright 2005, American Chemical Society. 


\subsection{Reduction of water (hydrogen generation)}

In metal chalcogenides, $\mathrm{ZnS}$ is a wide band gap material and CdSe possesses unsuitable band positions. On the other hand, CdS has gained importance due to its optimum band gap and suitable band positions ${ }^{11}$. Unfortunately, CdS undergoes photocorrosion under photocatalytic conditions and requires electron donors. Multicomponent heterostructures of type CdSe/CdS/Pt exhibit good hydrogen evolution yields $\left(40 \mathrm{mmol} \mathrm{h}^{-1} \mathrm{~g}^{-1}\right)^{12}$. This superior activity is attributed to the effective spatial separation of charges $^{12}$. Subjecting CdS to form type II heterostructures with $\mathrm{ZnO}$ and $\mathrm{TiO}_{2}$ results in charge carriers with longer life times.

We have recently investigated the photocatalytic properties $\mathrm{ZnO} / \mathrm{Pt} / \mathrm{CdS}$ heterostructures ${ }^{13}$. Interestingly, these heterostructures exhibit excellent hydrogen evolution activity due to its rational design, synthetic procedure employed and the relative configuration of the components. In this heterostructures, electrons and holes generated upon photoexcitation are confined to $\mathrm{ZnO}$ and $\mathrm{CdS}$ respectively due to their type II relative band alignment (Figure 5). Holes are consumed by using sacrificial scavengers such as $\mathrm{Na}_{2} \mathrm{~S}-\mathrm{Na}_{2} \mathrm{SO}_{3}$. Presence of Pt on
$\mathrm{Zn} 0$ enhances the activity nearly 7 times yielding a hydrogen evolution activity of $17.4 \mathrm{mmol} \mathrm{h}^{-1} \mathrm{~g}^{-1}$. Here replacing inorganic sacrificial with benzyl alcohol improves the photocataIytic activity in addition to oxidation products with an activity of $35 \mathrm{mmol} \mathrm{h}^{-1} \mathrm{~g}^{-1}$ (AQY 50\%). These heterostructures yield negligible hydrogen evolution in the higher wavelength region. The activity increases with increase in absorption of the CdS and the activity is attributed to the absorption of CdS. NiO in place of $\mathrm{Pt}$ in these heterostructures also yields activities comparable to $\mathrm{Pt}^{14}$. Similarly, $\mathrm{TiO}_{2} / \mathrm{NiO} / \mathrm{CdS}$ exhibits superior activity compared to $\mathrm{TiO}_{2} / \mathrm{Pt} / \mathrm{CdS}$ heterostructures ${ }^{15}$.

Role of morphology and surface area of the oxide nanostructures on the hydrogen evolution activity in $\mathrm{ZnO}\left(\mathrm{TiO}_{2}\right) / \mathrm{Pt} /$ $\mathrm{Cd}_{1-x} \mathrm{Zn}_{x} \mathrm{~S}$ heterostructures has been investigated. Photocatalytic activity increases with increase in surface area. Highest photocatalytic activities obtained with nanotubes in the case of $\mathrm{TiO}_{2}$ and nanorods in the case of $\mathrm{ZnO}{ }^{16}$.

Hydrogen evolution activity of $\mathrm{ZnO} / \mathrm{Pt} / \mathrm{Cd}_{1-y} \mathrm{Zn}_{y} \mathrm{~S}(y=$ $0.0,0.2$ ) heterostructures has been improved by cosubstitution of $\mathrm{N}$ and $\mathrm{F}$ in place of 0 in $\mathrm{ZnO}^{7}$. It has been shown that optical properties of $\mathrm{ZnO}$ and $\mathrm{CdS}$ are significantly altered by
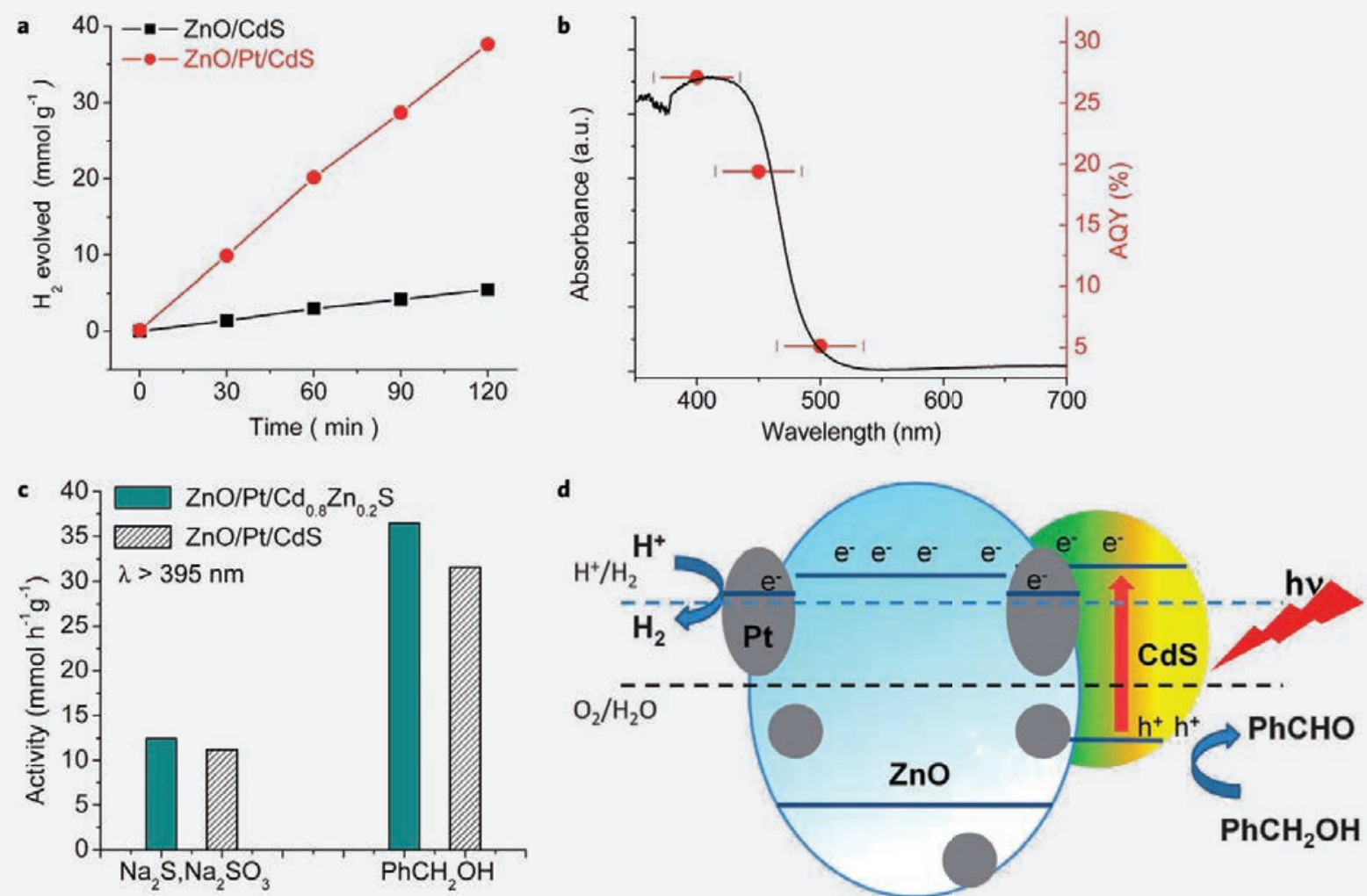

Figure 5. (a) Comparison of hydrogen evolution activity of $\mathrm{ZnO} / \mathrm{CdS}$ and $\mathrm{ZnO} / \mathrm{Pt} / \mathrm{dS}$. (b) Comparison of AQY with electronic absorption spectrum of ZnO/ $\mathrm{Pt} / \mathrm{Cd}_{0.8} \mathrm{Zn}_{0.2} \mathrm{~S}$. (c) Comparison of activity obtained with $\mathrm{Na}_{2} \mathrm{~S}_{-} \mathrm{Na}_{2} \mathrm{SO}_{3}$ with benzyl alcohol and (d) schematic representation of process of hydrogen evolution on $\mathrm{ZnO} / \mathrm{Pt} / \mathrm{Cd}_{0.8} \mathrm{Zn}{ }_{0.2} \mathrm{~S}$. Reproduced with permission from Ref. 13. 

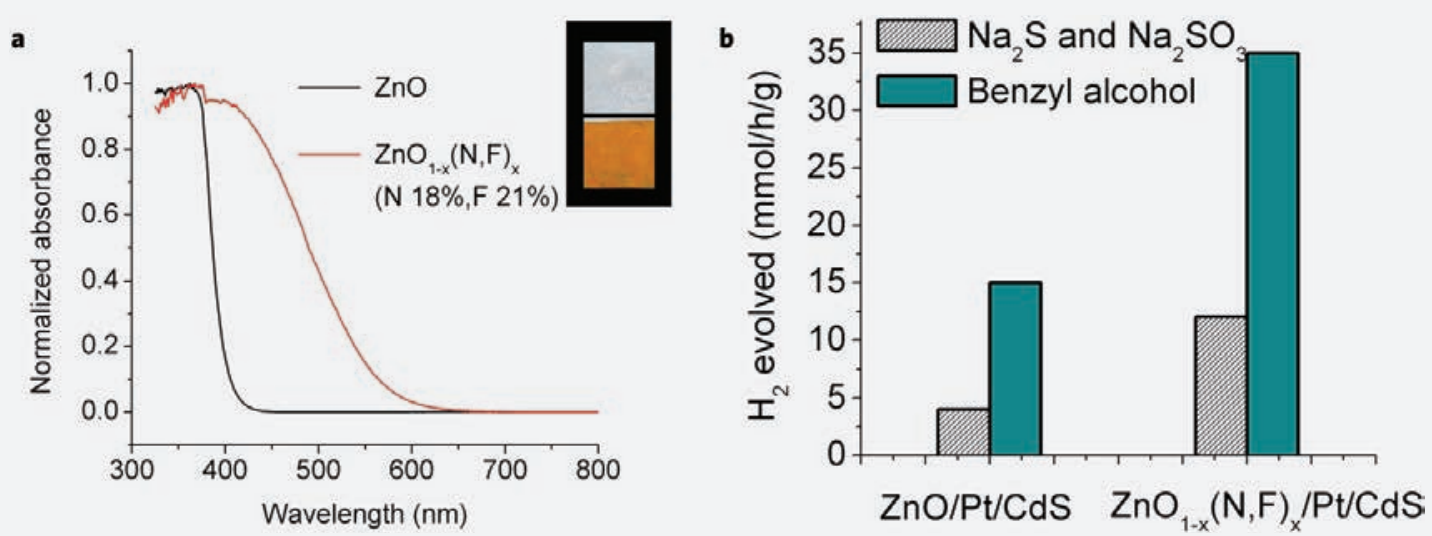

Figure 6. (a) Comparison of electronic absorption spectra of $\mathrm{ZnO}_{1_{1} x}(\mathrm{~N}, \mathrm{~F})_{x}$ nanostructures and $\mathrm{ZnO}$ and (b) comparison of effect of co-doping of $\mathrm{N}$ and $\mathrm{F}$ in $\mathrm{ZnO}$ on hydrogen evolution of $\mathrm{ZnO} / \mathrm{Pt} / \mathrm{CdS}$ using $\mathrm{Na}_{2} \mathrm{~S}$ and $\mathrm{Na}_{2} \mathrm{SO}_{3}$ or benzyl alcohol-acetic acid mixture under visible light irradiation. Reproduced with permission from Ref. 7.
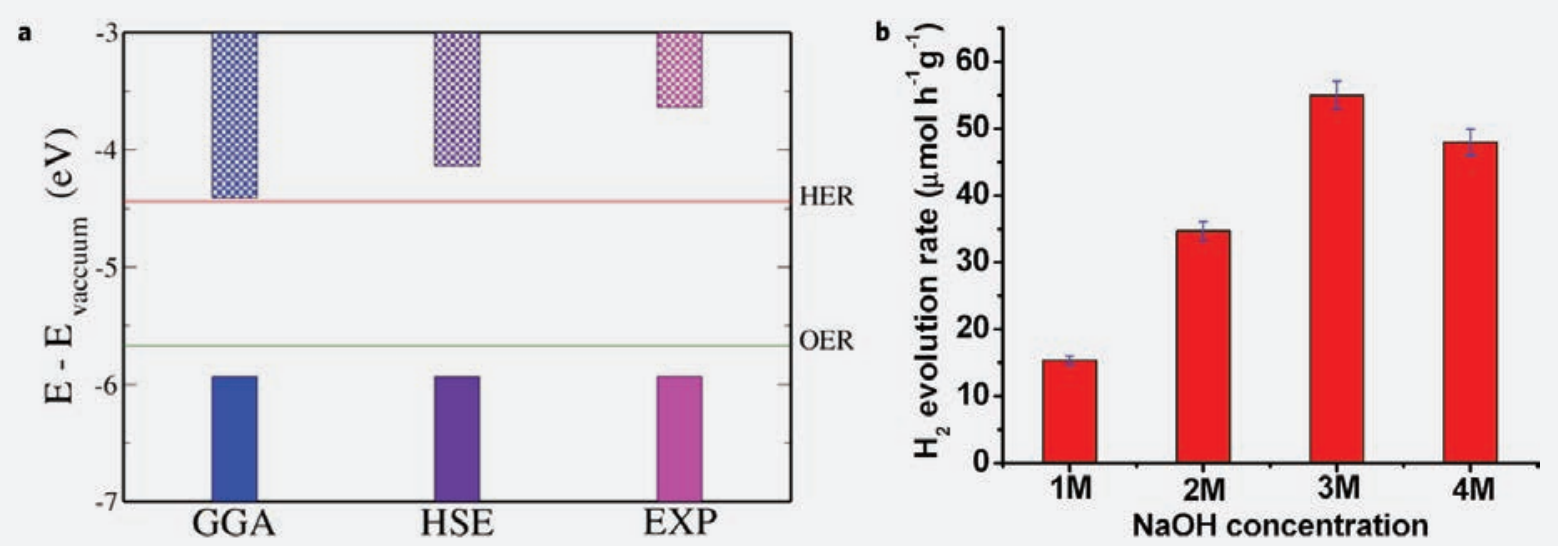

Figure 7. (a) Band edge positions obtained from first-principles calculations relative to water reduction and oxidation potentials and (b) variation of hydrogen evolution activity with $\mathrm{NaOH}$ concentration on $\mathrm{Cd}_{4} \mathrm{P}_{2} \mathrm{Cl}_{3}$. Reproduced with permission from Ref. 19.

cosubstitution of a trivalent anion along with a monovalent anion. As shown in Figure 6, the optical band gap of the material changes from 3.2 to $2.4 \mathrm{eV}$ up on $\mathrm{N}$ and $\mathrm{F}$ cosubstitution. Hydrogen evolution increases to $43 \mathrm{mmol} \mathrm{h}^{-1} \mathrm{~g}^{-1}$ upon $\mathrm{N}$ and $\mathrm{F}$ cosubstitution. Similarly, $\mathrm{N}$ and $\mathrm{Cl}$ cosubstitution also causes a decrease in the band gap from 3.2 to $2.0 \mathrm{eV}$ and enhances the photocatalytic activity ${ }^{17}$. $\mathrm{P}$ and $\mathrm{Cl}$ substitution in place of $\mathrm{S}$ has been carried out in $\mathrm{CdS}$ and $\mathrm{ZnS}^{18}$. States originating from $\mathrm{P}^{3-}$ ions cause a decrease in the band gap giving rise to improved photocatalytic activity. Progressive substitution of $\mathrm{P}$ and $\mathrm{Cl}$ in place of $\mathrm{S}$ in $\mathrm{CdS}$ finally results in the formation of $\mathrm{Cd}_{2} \mathrm{PCl}$. Roy et al. ${ }^{19}$ have investigated properties of $\mathrm{Cd}_{4} \mathrm{P}_{2} \mathrm{Cl}_{3} \cdot \mathrm{Cd}_{4} \mathrm{P}_{2} \mathrm{Cl}_{3}$ is a semiconductor with a band gap of $2.36 \mathrm{eV}$ which is close to that of $\mathrm{CdS}$. It also possesses suitable band positions for splitting of water. Interestingly $\mathrm{Cd}_{4} \mathrm{P}_{2} \mathrm{Cl}_{3}$ exhibits hydrogen evolution in the absence of any sacrificial hole scavenger unlike CdS (Figure 7). It is resistant to photocorrosion and has the potential to replace CdS. $\mathrm{N}$ and $\mathrm{C}$ codoping in $\mathrm{ZnS}$ red-shifts the visible light onset resulting in absorption activity for organic pollutant degradation. $\mathrm{P}$ and $\mathrm{Cl}$ cosubstitution in ZnS lowers the energy gap as predicted from theoretical calculations ${ }^{18}$.

Complete substitution of 0 in $\mathrm{ZnO}$ with $\mathrm{N}$ and $\mathrm{F}$ results in the formation of $\mathrm{Zn}_{2} \mathrm{NF}^{20}$. It has a slightly narrow band gap (2.8 eV) compared to $\mathrm{ZnO}$. Therefore, $\mathrm{Zn}_{2} \mathrm{NF} / \mathrm{Pt}$ exhibits visible-light induced hydrogen evolution in the presence of $\mathrm{Na}_{2} \mathrm{~S}-\mathrm{Na}_{2} \mathrm{SO}_{3}$. The band gap of the material varies with progressive substitution of $\mathrm{N}$ and $\mathrm{F}$ in $\mathrm{ZnO}$. It is a function of $\mathrm{N}$ 
a
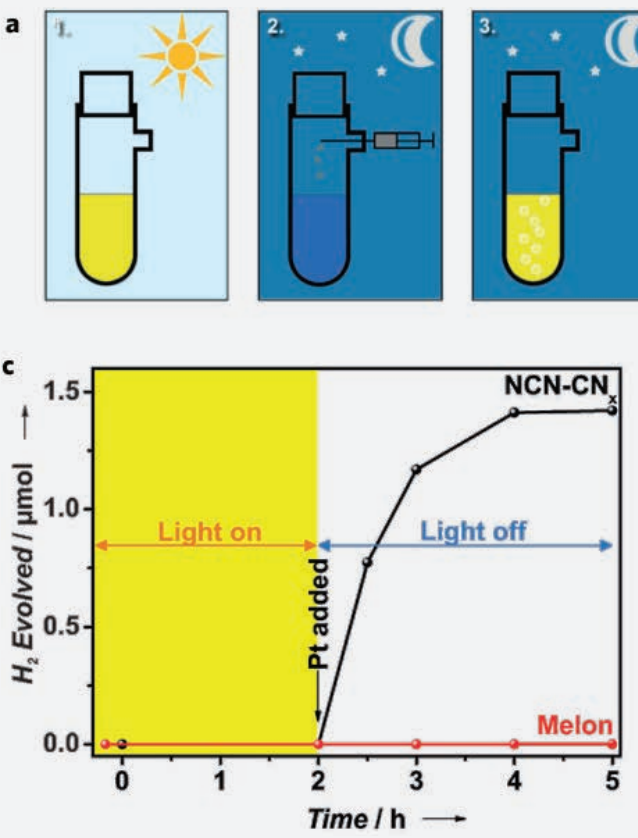

b
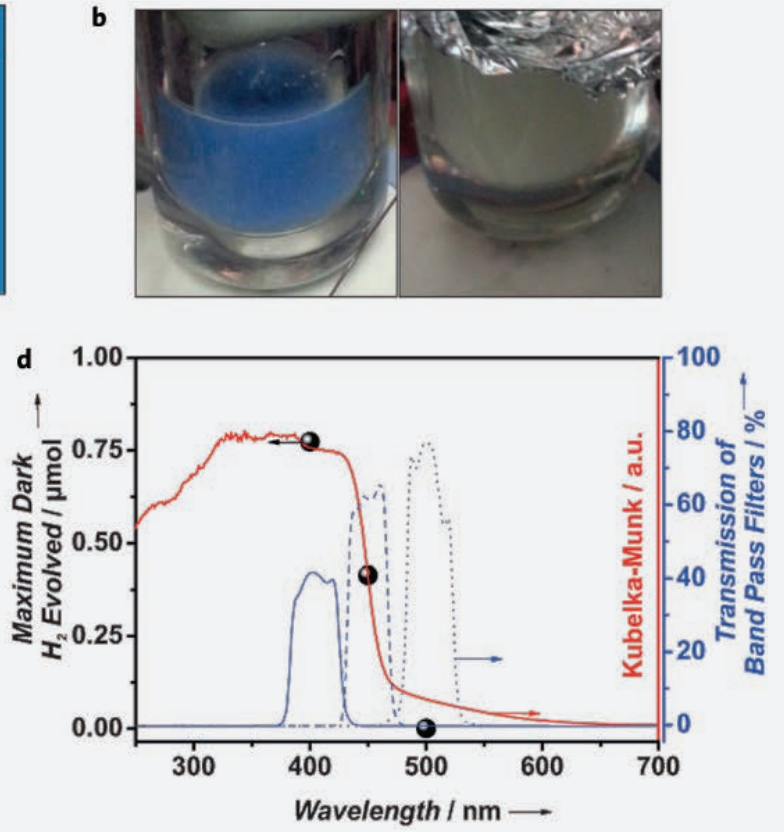

Figure 8. (a) Schematic representation of summary of the dark hydrogen evolution process. (b) Photographs of the "blue radical" (left) and its color reversal after the dark hydrogen evolution (right). (c) Plot representing the process of dark hydrogen evolution as a function of time. (d) Wavelength dependence of dark hydrogen evolved. Reproduced with permission from Ref. 21.

content with the least band gap of $2.0 \mathrm{eV}$ for the composition $\mathrm{ZnO}_{0.6} \mathrm{~N}_{0.2} \mathrm{~F}_{0.2}$.

Recently explored cyanamide-functionalized heptazinebased polymer $\left(\mathrm{NCN}-\mathrm{CN}_{x}\right)$ shows a time-delayed hydrogen evolution in dark similar to dark reactions in natural photosynthesis ${ }^{21}$. In this study, upon irradiation of light on NCN$\mathrm{CN}_{X}$ in the presence of electron donor (4-MBA) results in the formation of long-lived blue radicals (Figure 8). It produces hydrogen upon addition of the HER cocatalyst and material color reverted back to original color. The cyanamide moiety in $\mathrm{NCN}-\mathrm{CN}_{x}$ is crucial for the formation of the radical. The blue radical is not obtained in the presence of electron acceptors.

Layered materials have gained importance after the discovery of graphene. Although graphene is not active as a photocatalyst, it serves as an electron transport channel in several systems ${ }^{22}$. Among graphene analogues $\mathrm{MoS}_{2}$ is excellent as a cocatalyst since edge sites of $\mathrm{MoS}_{2}$ are active for the reduction of water ${ }^{23}$. The $1 \mathrm{~T}$ form of $\mathrm{MoS}_{2}$ with an activity of $30 \mathrm{mmol} \mathrm{h}^{-1} \mathrm{~g}^{-1}$ is more active compared to the stable $2 \mathrm{H}$ form (Figure 9). Here, the vacant d orbitals on $\mathrm{MoS}_{2}$ receive electrons and are utilized in the reduction of water.

\subsection{Oxidation of water (oxygen evolution)}

In the oxidation of water, holes get used for the oxidation of water to yield oxygen whereas electrons are used by sacrificial electron scavengers such as $\mathrm{AgNO}_{3}$ and $\mathrm{Na}_{2} \mathrm{~S}_{2} \mathrm{O}_{8}$. The electron scavengers get consumed in the process. In natural photosynthesis the WOC containing the $\mathrm{Mn}_{4} \mathrm{O}_{5} \mathrm{Ca}$ cluster catalyzes the oxidation of water. It has a cubane structure in the intermediate form and upon donation of four electrons to PSII, it restores back to its resting state by releasing oxygen and four protons ${ }^{24}$. It is important to note that turnover frequency of this PSII-WOC is very high $\left(5 \times 10^{2} \mathrm{~s}^{-1}\right)$ and life times of nearly 30 minutes. The metal-oxocubane structure was believed to be critical for the activity and therefore research was focused on developing such systems. It has, however, been found recently that the electron configuration of $\mathrm{Mn}$ or $\mathrm{Co}$ ions is more important than structural factors ${ }^{25}$. In $\mathrm{Mn}^{3+}$ and $\mathrm{Co}^{3+}$ containing compounds presence of one $e_{g}$ electron is found to be crucial for the oxidation of water. In $\mathrm{Mn}_{2} \mathrm{O}_{3}$ and $\mathrm{LaMnO}_{3}, \mathrm{Mn}^{3+}$ has the $t_{2 g}{ }^{3} e_{g}{ }^{1}$ configuration whereas $\mathrm{Co}^{3+}$ in the intermediate spin state has the $t_{2 g}{ }^{5} e_{g}{ }^{1}$ configuration. These are best for the photocatalytic oxidation of water. As shown in Figure 10, increase in Li content in $\mathrm{Li}_{x} \mathrm{CO}_{2} \mathrm{O}_{4}$ decreases the relative charge on $\mathrm{Co}$ and resulting in the formation of $\mathrm{Co}^{3+}$ with $x=2$ i.e. $\mathrm{Li}_{2} \mathrm{CO}_{2} \mathrm{O}_{4}$. Similarly, La$\mathrm{CoO}_{3}$ wherein $\mathrm{Co}$ exists in trivalent state exhibit good oxygen evolution activity with TOF of $1.4 \times 10^{-3} \mathrm{~s}^{-1} \cdot \mathrm{Co}^{3+}$ containing compounds shows superior activity over $\mathrm{Mn}^{3+}$ containing compounds. 
a $2 \mathrm{H}-\mathrm{MoS}_{2}$

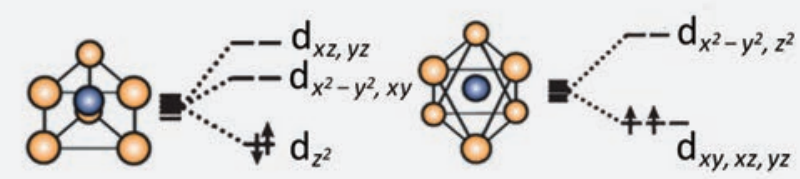

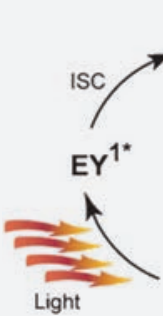

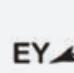
TEOA

$1 \mathrm{~T}-\mathrm{MoS}_{2}$

$d_{x y, x z, y z}$<smiles></smiles>

Figure 9. (a) Electronic configuration of $2 \mathrm{H}-\mathrm{MOS}_{2}$ and $1 \mathrm{~T}-\mathrm{MoS}_{2}$ induced by the crystal-field splitting and proposed mechanism of hydrogen evolution on $1 \mathrm{~T}-\mathrm{MoS}_{2}$. (b) Time course of $\mathrm{H}_{2}$ evolved by 1T-MoS ${ }_{2}$. Reproduced with permission from Ref. 23. Copyright 2013, Wiley-VCH Verlag GmbH \& Co. KGaA, Weinheim.
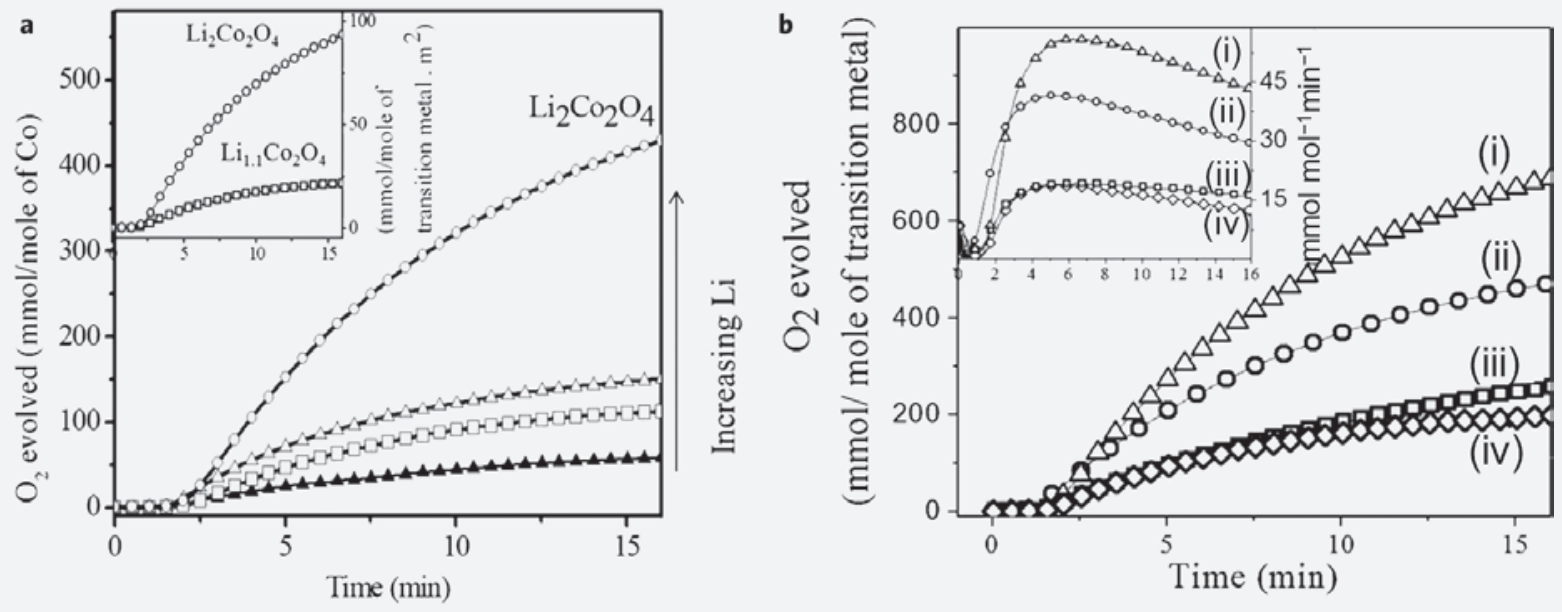

Figure 10. (a) Comparison of amount of $\mathrm{O}_{2}$ evolved by $\mathrm{Li}_{x} \mathrm{CO}_{2} \mathrm{O}_{4}$ with different amount of $\mathrm{Li}$. (O) $\mathrm{Li}_{2} \mathrm{CO}_{2} \mathrm{O}_{4}$ and (口) $\mathrm{Li}_{1.1} \mathrm{CO}_{2} \mathrm{O}_{4}$. (b) Comparison of amount of $\mathrm{O}_{2}$ evolved in (i) $\mathrm{LaCOO}_{3}$, (ii) $\mathrm{Li}_{2} \mathrm{CO}_{2} \mathrm{O}_{4}$, (iii) $\mathrm{Mn}_{2} \mathrm{O}_{3}$, and (iv) $\mathrm{LaMnO}_{3}$. Reproduced with permission from Ref. 25.

Semiconductor-based photocatalysts such $\mathrm{BiVO}_{4}$, $\mathrm{WO}_{3}, \mathrm{Fe}_{3} \mathrm{O}_{4}$ are suitable for water oxidation, we shall discuss $\mathrm{BiVO}_{4}-\mathrm{Pt}^{-} \mathrm{MnO}_{x}$ system here (Figure 11) ${ }^{26}$. In BiVO ${ }_{4}$ the electrons migrate to the (010) facet and the holes migrate to the (110) facet due to the difference in their relative energies. Photodeposition of both the cocatalysts $\left(\mathrm{Pt}, \mathrm{MnO}_{x}\right)$ results in selective deposition Pt on the (010) and $\mathrm{MnO}_{X}$ on the (110) facet. Selective deposition of photocatalysts shows 2 orders of superior photocatalytic activity over random deposition.

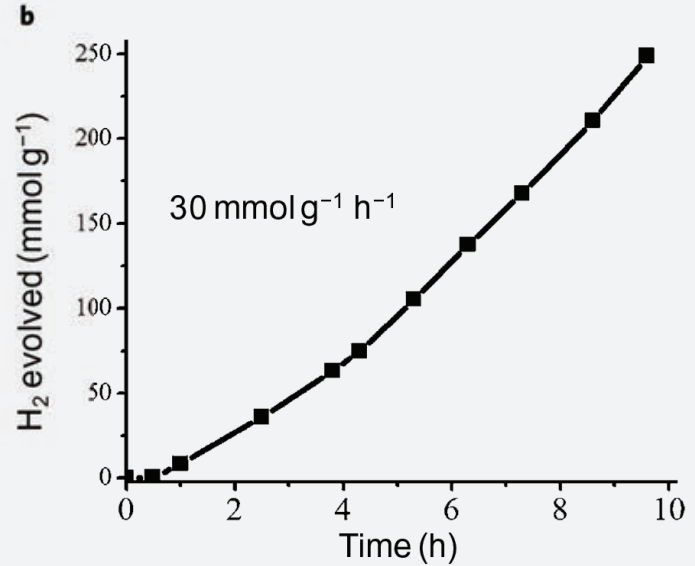



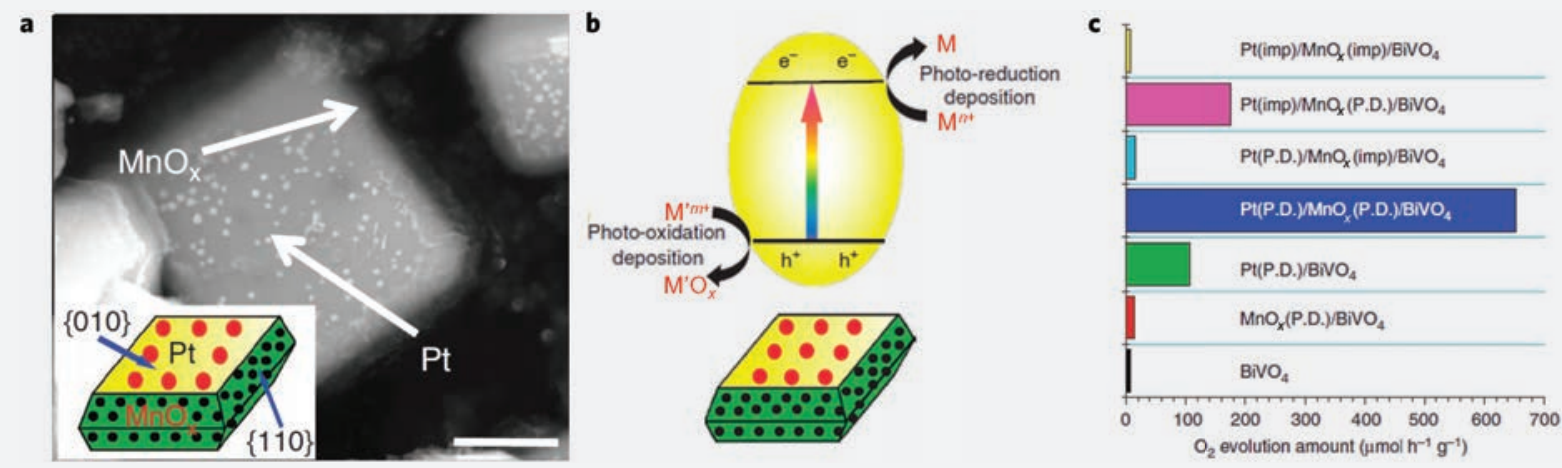

\begin{abstract}
Figure 11. (a) SEM images of $\mathrm{BiVO}_{4}-\mathrm{Pt}-\mathrm{MnO}_{x}$ (b) Schematic representation of mechanism of water splitting on BiVO ${ }_{4}^{-P t-M n O_{x}}$ (c) Comparison of photocatalytic activity of $\mathrm{BiVO}_{4}-\mathrm{Pt}-\mathrm{MnO}_{x}$, with the activities of other related photocatalysts. Reproduced with permission from Ref. 26. Copyright 2013, Macmillan Publishers Limited.
\end{abstract}

reduced in the presence of solar irradiation to form $\mathrm{CO}$ and organic products $\left(\mathrm{HCHO}, \mathrm{HCOOH}, \mathrm{CH}_{3} \mathrm{OH}, \mathrm{CH}_{4}\right.$, etc). It is a sustainable process since it only uses $\mathrm{CO}_{2}, \mathrm{H}_{2} \mathrm{O}$ and solar energy. Since $\mathrm{CO}_{2}$ is a stable compound $\left(\Delta G_{f}^{0}=394.4 \mathrm{~kJ} \mathrm{~mol}^{-1}\right)$, it is difficult to reduce directly. Mechanism of $\mathrm{CO}_{2}$ reduction has been discussed in detail in the literature ${ }^{27,28}$.

The process of photocatalytic $\mathrm{CO}_{2}$ reduction on a semiconductor photocatalyst is illustrated in Figure $12^{29}$. Photogenerated electrons are utilized in the reduction of $\mathrm{CO}_{2}$ and holes are utilized for the oxidation of water. Single electron transfer to $\mathrm{CO}_{2}$ to form $\mathrm{CO}_{2}{ }^{--}$is associated with a highly negative reduction potential $(-1.85 \mathrm{~V}$ vs. SHE) due to the change in hybridization of $\mathrm{C}$ from $\mathrm{sp}^{2}$ to $\mathrm{sp}^{327}$. It undergoes proton-coupled electron transfer (PCET) wherein electron transfer to $\mathrm{CO}_{2}$ is coupled with a proton transfer. Reduction of water always competes

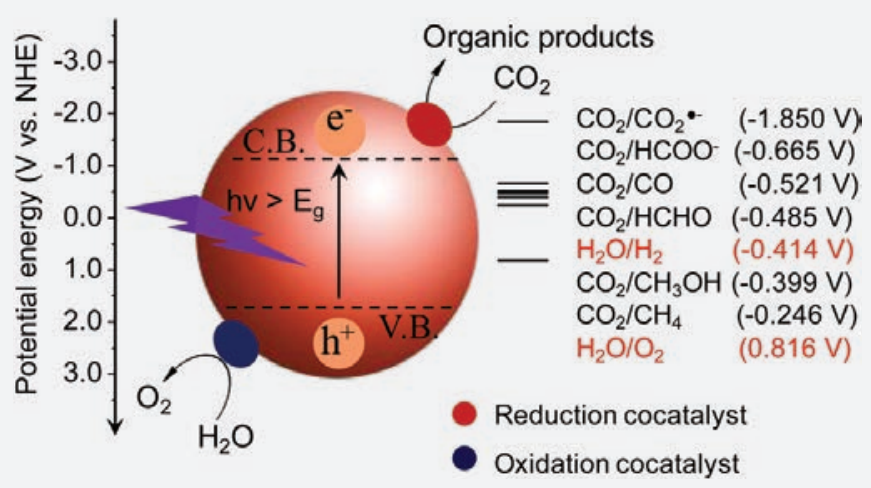

Figure 12. Schematic representation of process of photocatalytic reduction of $\mathrm{CO}_{2}$ Reproduced with permission from Ref. 29. with the reduction of $\mathrm{CO}_{2}$ since the reduction potentials for PCET reactions are close to the water reduction potential.

$\mathrm{CO}_{2}$ reduction is usually carried out in gaseous phase with humidified $\mathrm{CO}_{2}$ and in the liquid phase with $\mathrm{CO}_{2}$ saturated aqueous $\mathrm{NaOH}$ or bicarbonate solution. $\mathrm{TiO}_{2}$ has been extensively studied for purpose of photocatalytic reduction of $\mathrm{CO}_{2}$. Cation as well anion doped $\mathrm{TiO}_{2}$ materials have also been employed for $\mathrm{CO}_{2}$ reduction. Anion doped $(\mathrm{N}) \mathrm{TiO}_{2}$ as well as cation-doped $(\mathrm{Ce}) \mathrm{TiO}_{2}$ exhibit superior activity compared to undoped $\mathrm{TiO}_{2}$, anion doping being more favor$\mathrm{able}^{27}$. Deposition of $\mathrm{Pt}, \mathrm{Au}, \mathrm{Pd}, \mathrm{Ag}$, Cu, etc. on the photocatalysts enhances the activity of photochemical reduction of $\mathrm{CO}_{2}$. Pt mostly favors the reduction of water and is poisoned by $\mathrm{CO}$. Ag exhibits superior $\mathrm{CO}_{2}$ reduction activity owing to weak binding with the $\mathrm{CO}^{27}$.

Zinc germanium oxynitride obtained by nitridation of $\mathrm{Zn}_{2} \mathrm{GeO}_{4}$ has a band gap $2.7 \mathrm{eV}$ and exhibit production rate of $2.7 \mathrm{ppm} \mathrm{g}^{-1} \mathrm{~h}^{-1}$ of $\mathrm{CH}_{4}$ from $\mathrm{CO}_{2}$ under visible light irradiation ${ }^{30}$. $\mathrm{Zn}_{2} \mathrm{AlO}_{4}$-modified $\mathrm{ZnGaNO}$ also exhibit $9.2 \mu \mathrm{mol}$ $\mathrm{h}^{-1} \mathrm{~g}^{-1}$ of $\mathrm{CH}_{4}$ under visible-light irradiation ${ }^{31}$. In both these materials the visible light activity is due to the narrow band gaps compared to the parent oxides. Type II heterostructures such as $\mathrm{TiO}_{2} / \mathrm{CdSe}$ with Pt effectively drives the reduction of $\mathrm{CO}_{2}$ producing methane $\left(48 \mathrm{ppm} \mathrm{h}^{-1}\right.$ $\left.\mathrm{g}^{-1}\right)^{32}$. In these structures, visible-light is absorbed by the CdS and the interface between CdSe and $\mathrm{TiO}_{2}$ causes charge separation. In a recent study, we have employed bimetallic alloys containing heterostructures for the $\mathrm{CO}_{2}$ reduction in the presence of 2-propanol ${ }^{33}$. $\mathrm{Ag}_{1-x} \mathrm{Cu}_{x}$ alloys found to be superior to $\mathrm{Ag}_{1-x} \mathrm{Au}_{x}$, 
$\mathrm{Au}, \mathrm{Ag}$ and Pt for catalysis. These heterostructures exhibit $\mathrm{CO}_{2}$ reduction activity in the absence of a hole-scavenger in gas-phase under direct sunlight.

\section{CONCLUDING REMARKS}

There has been extensive research on developing photocatalysts for water splitting, hydrogen as well as oxygen evolution and reduction of $\mathrm{CO}_{2}$. Visible-light responsive materials have received greater attention. Nanomaterials with narrow band gaps also show good photocatalytic activity. Heterostructures of type II are particularly effective in solar conversion. They provide charge carriers with longer life-times due to their relative band positions. Interfaces between the components in the heterostructures play a crucial role. For the purpose of reducing the band gap of wide band gap materials, aliovalent anion cosubstitution is found to be effective. Thus cosubstitution of trivalent anions $\left(\mathrm{N}^{3-}, \mathrm{P}^{3-}\right)$ and monovalent anions $\left(\mathrm{F}^{-}\right.$, $\left.\mathrm{Cl}^{-}\right)$in place of divalent anions $\left(0^{2-}, \mathrm{S}^{2-}\right)$ reduces the band gaps due to states originating from trivalent anions. Graphene acts as a channel for charge transport in Z-scheme photocatalysts. $\mathrm{MoS}_{2}$ catalyzes the reduction of water due to its unique edge sites.

The activity of photocatalysts is limited by either poor light absorption or charge separation. Presence of defects decreases the life-times of charge carriers and it is therefore important to have fewer defects. Developing multicomponent structures to simultaneously produce hydrogen and oxygen from water is important to avoid sacrificial scavengers. These catalysts should be based on earth abundant elements to make the process practicable. Photocatalytic reduction of $\mathrm{CO}_{2}$ has been carried out by using on several systems including doped oxides, oxynitrides and heterostructures. Heterostructures containing bimetallic alloys such as $\mathrm{Ag}_{1-x} \mathrm{Cu}_{x}$ are also effective for the reduction of $\mathrm{CO}_{2}$. Selectivity of the products and suppression of the competing water reduction are crucial for developing photocatalysts for the reduction of $\mathrm{CO}_{2}$.

\section{REFERENCES}

1. Maitra, U., Lingampalli, S.R. \& Rao, C.N.R. Artificial photosynthesis and the splitting of water to generate hydrogen. Curr. Sci. 106, 518 (2014).

2. Osterloh, F.E. Inorganic nanostructures for photoelectrochemical and photocatalytic water splitting. Chem. Soc. Rev. 42, 2294 (2013).

3. Rao, C.N.R. \& Lingampalli, S.R. Generation of hydrogen by visible-light induced water-splitting with the use of semiconductors and dyes. Small 12, 16 (2016).

4. Kronawitter, C.X., Vayssieres, L., Shen, S., Guo, L., Wheeler, D.A., Zhang, J.Z., Antoun, B.R. \& Mao, S.S. A perspective on solar-driven water splitting with all-oxide hetero-nanostructures. Energy Environ. Sci. 4, 3889 (2011).
5. Kudo, A. \& Miseki, Y. Heterogeneous photocatalyst materials for water splitting. Chem. Soc. Rev. 38, 253 (2009).

6. Tee, S.Y., Win, K.Y., Teo, W.S., Koh, L.D., Liu, S., Teng, C.P. \& Han, M.Y. Recent progress in energy-driven water splitting. Adv. Sci. 4, 160037 (2017).

7. Lingampalli, S.R. \& Rao, C.N.R. Remarkable improvement in visible-light induced hydrogen generation by $\mathrm{ZnO} / \mathrm{Pt} / \mathrm{Cd}_{1-y} \mathrm{Zn}_{y} \mathrm{~S}$ heterostructures through substitution of $\mathrm{N}$ and $\mathrm{F}$ in ZnO. J. Mater. Chem. A 2, 7702 (2014).

8. Kumar, N., Maitra, U., Hegde, V.I., Waghmare, U.V., Sundaresan, A. \& Rao, C.N.R. Synthesis, characterization, photocatalysis, and varied properties of $\mathrm{TiO}_{2}$ cosubstituted with nitrogen and fluorine. Inorg. Chem. 52, 10512 (2013).

9. Seh, Z.W., Liu, S., Low, M., Zhang, S.-Y., Liu, Z., Mlayah, A. \& Han, M.-Y. Janus Au- $\mathrm{TiO}_{2}$ photocatalysts with strong localization of plasmonic near-fields for efficient visible-light hydrogen generation. Adv. Mater. 24, 2310 (2012).

10. Maeda, K., Teramura, K., Lu, D., Takata, T., Saito, N., Inoue, Y. \& Domen, K. Photocatalyst releasing hydrogen from water. Nature 440, 295 (2006).

11. Tang, Z.-R., Han, B., Han, C. \& Xu, Y.-J. One dimensional CdS based materials for artificial photoredox reactions. J. Mater. Chem. A 5, 2387 (2017).

12. Amirav, L. \& Alivisatos, A.P. Photocatalytic hydrogen production with tunable nanorod heterostructures. J. Phys. Chem. Lett. 1, 1051 (2010).

13. Lingampalli, S.R., Gautam, U.K. \& Rao, C.N.R. Highly efficient photocatalytic hydrogen generation by solutionprocessed $\mathrm{ZnO} / \mathrm{Pt} / \mathrm{CdS}, \mathrm{ZnO} / \mathrm{Pt} / \mathrm{Cd}_{1-x} \mathrm{Zn}_{x} \mathrm{~S}$ and $\mathrm{ZnO} / \mathrm{Pt} /$ $\mathrm{CdS}_{1-x} \mathrm{Se}_{x}$ hybrid nanostructures. Energy Environ. Sci. 6, 3589 (2013).

14. Lingampalli, S.R., Roy, A., Ikram, M. \& Rao, C.N.R. Visible-light induced hydrogen generation with $\mathrm{ZnO} / \mathrm{NiO} /$ $\mathrm{Cd}_{1-x} \mathrm{Zn}_{x} \mathrm{~S}(x=0.0,0.2)$ heterostructures. Chem. Phys. Lett. 610-611, 316 (2014).

15. Roy, A., Lingampalli, S.R., Nassar, I.M. \& Rao, C.N.R. Effectiveness of $\mathrm{NiO}$ in replacing $\mathrm{Pt}$ in the photochemical generation of hydrogen by $\left(\mathrm{TiO}_{2}\right)_{1-x}(\mathrm{NiO})_{x} / \mathrm{Cd}_{0.8} \mathrm{Zn}_{0.2} \mathrm{~S}$ heterostructures. Solid State Commun. 243, 1 (2016).

16. Roy, A., Lingampalli, S.R., Saha, S. \& Rao, C.N.R. Effects of morphology and surface area of the oxide nanostructures on the visible-light induced generation of hydrogen in $\mathrm{ZnO}\left(\mathrm{TiO}_{2}\right) / \mathrm{Cd}_{1-x} \mathrm{Zn}_{x} \mathrm{~S}$ and $\mathrm{ZnO}\left(\mathrm{TiO}_{2}\right) / \mathrm{Pt} / \mathrm{Cd}_{1-x} \mathrm{Zn}_{x} \mathrm{~S}$ heterostructures $(x=0.0,0.2)$. Chem. Phys. Lett. 637, 137 (2015).

17. Lingampalli, S.R., Prasad, S., Manjunath, K., Ayyub, M.M., Vishnoi, P., Waghmare, U.V. \& Rao, C.N.R. Effects of substitution of aliovalent $\mathrm{N}^{3-}$ and $\mathrm{Cl}^{-}$ions in place of $0^{2-}$ in $\mathrm{ZnO}$ : Properties of $\mathrm{ZnO}_{1-x-y} \mathrm{~N}_{x} \mathrm{Cl}_{y}(x, y=0.0-0.5)$. Eur. J. Inorg. Chem. 2017, 2377 (2017). 
18. Kouser, S., Lingampalli, S.R., Chithaiah, P., Roy, A., Saha, S., Waghmare, U.V. \& Rao, C.N.R. Extraordinary changes in the electronic structure and properties of $\mathrm{CdS}$ and ZnS by anionic substitution: Co-substitution of $\mathrm{P}$ and $\mathrm{Cl}$ in place of S. Angew. Chem. Int. Ed. 54, 8149 (2015).

19. Roy, A., Shenoy, U.S., Manjunath, K., Vishnoi, P., Waghmare, U.V. \& Rao, C.N.R. Structure and properties of $\mathrm{Cd}_{4} \mathrm{P}_{2} \mathrm{Cl}_{3}$, an analogue of CdS. J. Phys. Chem. C 120, 15063 (2016).

20. Lingampalli, S.R., Manjunath, K., Shenoy, S., Waghmare, U.V. \& Rao, C.N.R. $\mathrm{Zn}_{2} \mathrm{NF}$ and related analogues of $\mathrm{Zn0}$. J. Am. Chem. Soc. 138, 8228 (2016).

21. Lau, V.W.-H., Klose, D., Kasap, H., Podjaski, F., Pignié, M.C., Reisner, E., Jeschke, G. \& Lotsch, B.V. Dark photocatalysis: Storage of solar energy in carbon nitride for timedelayed hydrogen generation. Angew. Chem. Int. Ed. 56, 510 (2017).

22. Li, Q., Guo, B., Yu, J., Ran, J., Zhang, B., Yan, H. \& Gong, J.R. Highly efficient visible-light-driven photocatalytic hydrogen production of CdS-cluster-decorated graphene nanosheets. J. Am. Chem. Soc. 133, 10878 (2011).

23. Maitra, U., Gupta, U., De, M., Datta, R., Govindaraj, A. \& Rao, C.N.R. Highly effective visible-light-induced $\mathrm{H}_{2}$ generation by single-layer $1 \mathrm{~T}-\mathrm{MoS}_{2}$ and a nanocomposite of few-layer $2 \mathrm{H}-\mathrm{MoS}_{2}$ with heavily nitrogenated graphene. Angew. Chem. Int. Ed. 52, 13057 (2013).

24. Cox, N., Pantazis, D.A., Neese, F. \& Lubitz, W. Artificial photosynthesis: Understanding water splitting in nature. Interface Focus 5, 20150009 (2015).

25. Maitra, U., Naidu, B.S., Govindaraj, A. \& Rao, C.N.R. Importance of trivalency and the $e_{g}{ }^{1}$ configuration in the photocatalytic oxidation of water by $\mathrm{Mn}$ and $\mathrm{Co}$ oxides. Proc. Natl. Acad. Sci., U.S.A. 110, 11704 (2013).

26. Li, R., Zhang, F., Wang, D., Yang, J., Li, M., Zhu, J., Zhou, X., Han, H. \& Li, C. Spatial separation of photogenerated electrons and holes among $\{010\}$ and $\{110\}$ crystal facets of $\mathrm{BiVO}_{4}$. Nat. Commun. 4, 1432 (2013).

27. White, J.L., Baruch, M.F., Pander lii, J.E., Hu, Y., Fortmeyer, I.C., Park, J.E., Zhang, T., Liao, K., Gu, J., Yan, Y., Shaw, T.W., Abelev, E. \& Bocarsly, A.B. Light-driven heterogeneous reduction of carbon dioxide: Photocatalysts and photoelectrodes. Chem. Rev. 115, 12888 (2015).

28. Li, K., Peng, B. \& Peng, T. Recent advances in heterogeneous photocatalytic $\mathrm{CO}_{2}$ conversion to solar fuels. ACS Catal. 6, 7485 (2016).

29. Lingampalli, S.R., Ayyub, M.M. \& Rao, C.N.R. Recent progress in the photocatalytic reduction of carbon dioxide. ACS Omega 2, 2740 (2017).

30. Zhang, N., Ouyang, S., Kako, T. \& Ye, J. Mesoporous zinc germanium oxynitride for $\mathrm{CO}_{2}$ photoreduction under visible light. Chem. Commun. 48, 1269 (2012).

31. Yan, S., Yu, H., Wang, N., Li, Z. \& Zou, Z. Efficient conversion of $\mathrm{CO}_{2}$ and $\mathrm{H}_{2} \mathrm{O}$ into hydrocarbon fuel over $\mathrm{ZnAl}_{2} \mathrm{O}_{4}-$ modified mesoporous $\mathrm{ZnGaNO}$ under visible light irradiation. Chem. Commun. 48, 1048 (2012).

32. Wang, C., Thompson, R.L., Baltrus, J. \& Matranga, C. Visible light photoreduction of $\mathrm{CO}_{2}$ using $\mathrm{CdSe} / \mathrm{Pt} / \mathrm{TiO}_{2}$ heterostructured catalysts. J. Phys. Chem. Lett. 1, 48 (2009).

33. Lingampalli, S.R., Ayyub, M.M., Magesh, G. \& Rao, C.N.R. Photocatalytic reduction of $\mathrm{CO}_{2}$ by employing $\mathrm{ZnO} /$ $\mathrm{Ag}_{1-x} \mathrm{Cu}_{x} / \mathrm{CdS}$ and related heterostructures. Chem. Phys. Lett. 691, 28 (2018). 